\section{Identificação e distribuição espacial de imóveis- chave de Aedes aegypti no bairro Porto Dantas, Aracaju, Sergipe, Brasil entre 2007 e 2008}

\author{
Identification and spatial distribution of key \\ premises for Aedes aegypti in the Porto Dantas \\ neighborhood, Aracaju, Sergipe State, Brazil, \\ 2007-2008
}

\author{
Identificación y distribución espacial de \\ recipientes-clave de Aedes aegypti en el barrio \\ Porto Dantas, Aracaju, Sergipe, Brasil entre \\ 2007 y 2008
}

Letícia Silva Marteis 1

Lizandra Makowski Steffler 2

Karina Conceição Gomes Machado de Araújo 2 Roseli La Corte dos Santos 2

\footnotetext{
1 Universidade de São Paulo, São Paulo, Brasil.

2 Universidade Federal de Sergipe, São Cristóvão, Brasil.

Correspondência

R. L. C. Santos

Universidade Federal de Sergipe.

Av. Marechal Rondon $s / n$ São Cristóvão, SE 49100-000, Brasil.

rlacorte@ufs.br
}

\begin{abstract}
Currently the best way to avoid new dengue epidemics is to control the mosquito vector Aedes aegypti. This study thus aimed to identify and analyze the spatial distribution of "key premises" for Ae. aegypti in Aracaju, Sergipe State, Brazil. Three entomological surveys were performed prior to, during, and after the dengue epidemic and in different conditions of precipitation: the end of the rainy season, beginning of the rainy season, and the dry season. Key premises were identified by positivity in more than one survey and presence of pupae. Spatial distribution and dispersal of mosquitoes used analysis of point patterns, with the kernel and buffer density estimator. Key premises were responsible for maintaining infestation of the area, independently of environmental conditions and the period in the epidemic, serving as foci generating mosquitoes that can spread to areas adjacent to the neighborhood. Thus, in order to be more effective, vector control measures should target these properties.
\end{abstract}

Dengue; Aedes; Geographic Information Systems; Vector Control

\section{Resumo}

A melhor forma de evitar novas epidemias de dengue é controlar o vetor, o mosquito Aedes aegypti. Assim, este estudo objetivou identificar e analisar a distribuição espacial dos imóveischave para Ae. aegypti em Aracaju, Sergipe, Brasil. Para isso, três levantamentos entomológicos foram realizados em períodos antes, durante e após a epidemia de dengue e em diferentes condições de precipitação: fim do período chuvoso, início da estação chuvosa e estiagem. Para identificar os imóveis-chave, foram consideradas as variáveis: positividade em mais de um levantamento e presença de pupas; e para verificar a distribuição espacial e dispersão dos mosquitos, foi realizada análise de padrões pontuais, por meio do estimador de densidade de kernel $e$ buffer. Constatou-se que os imóveis-chave são responsáveis pela manutenção da infestação na localidade independente das condições ambientais e do período epidêmico e são focos geradores de mosquitos que podem se dispersar para áreas vizinhas ao bairro. Dessa forma, as ações de controle vetorial, para serem mais efetivas, devem ser direcionadas para esses imóveis.

Dengue; Aedes; Sistemas de Informação

Geográfica; Controle de Vetores 


\section{Introdução}

A dengue persiste como sério problema de saúde pública, e o controle da doença continua direcionado ao vetor, o mosquito Aedes aegypti, elo vulnerável na cadeia de transmissão da doença. No entanto, as investidas do Programa de Controle da Dengue em reduzir as altas infestações pelo vetor não são capazes de evitar a ocorrência de epidemias de dengue 1,2,3. O Ae. aegypti é um culicídeo registrado em todos os estados brasileiros, evidenciando a necessidade de conhecimento mais eficaz quanto ao seu controle 4,5,6.

Os métodos de avaliação da infestação por Ae. aegypti mais utilizados ainda se concentram em indicadores larvários como os índices de infestação predial, de recipiente e de Breteau, devido à facilidade em trabalhar com larvas. A coleta de culicídeos adultos, devido aos elevados custos e demora na realização do trabalho, só é realizada em situações específicas ou quando envolve estudos mais detalhados 7. Porém, vários estudos mostram a ineficiência dos índices larvários em estimar a densidade e a produtividade dos criadouros, já tendo sido observados surtos da doença em locais onde os índices calculados não demonstravam risco 8,9,10. Assim, é necessário estabelecer índices que melhor reflitam a produção de mosquitos alados e que identifiquem a real situação epidemiológica de cada região 11 .

A identificação de imóveis contendo recipientes com potencial produtivo, nos quais são observados imaturos no estágio de desenvolvimento de pupas, é importante para caracterizar áreas que oferecem maior risco de infestação pelo vetor 12. A associação entre levantamento entomológico e geoprocessamento vem sendo utilizada como ferramenta útil para identificar os locais com maior potencial de transmissão da dengue e evitar a ocorrência de epidemias, uma vez que, por meio do mapeamento da área, é possível identificar áreas de risco e melhor direcionar as ações de controle do vetor 4,11,13,14.

O Sistema de Informação Geográfica (SIG) constitui poderosa ferramenta utilizada em atividades de vigilância ambiental em saúde para melhor entender a dinâmica da infestação por Ae. aegypti. As informações georreferenciadas permitem realizar análises complexas, visto que integram a criação de banco de dados e elaboração de mapas de risco, para, então, melhor avaliar as atividades em saúde pública, além de trabalhar com diversas abordagens as diferentes realidades de uma determinada área 14,15,16,17,18.

Em 2008, Sergipe foi um dos estados brasileiros mais afetados com epidemias de dengue. Foram confirmados 28.543 casos da doença, sendo que 12.160 deles ocorreram no mês de abril, no auge da epidemia, o que representou aumento de $2.311 \%$ em comparação com 2007, ano em que 1.235 notificações foram registradas 19 . Assim, o estudo dos imóveis com persistência de focos do vetor e maior produtividade de mosquitos alados é fundamental para gerar conhecimento que melhor direcione as atividades de controle vetorial. Além disso, a rápida dispersão e colonização de Ae. aegypti em todo o território nacional reforça a necessidade de desenvolver mais estudos sobre esse vetor. Diante do exposto, o objetivo deste estudo foi identificar e analisar a distribuição espacial dos imóveis-chave para $A e$. aegypti em área urbana do Município de Aracaju, Sergipe, Brasil.

\section{Metodologia}

\section{Área de estudo}

O estudo foi realizado no bairro Porto Dantas ( $10^{\circ} 52^{\prime} 40$ ”'S e $37^{\circ} 03^{\prime} 42^{\prime} \mathrm{O}$ ), em Aracaju. Geograficamente, o Município de Aracaju está localizado no litoral da Região Nordeste, à margem direita do rio Sergipe. O tipo climático é o megatérmico úmido e subúmido, com temperatura e precipitação médias anuais de $26^{\circ} \mathrm{C}$ e $1.590 \mathrm{~mm}$, respectivamente. $\mathrm{O}$ período chuvoso compreende os meses de março a agosto, e, de janeiro a março, meses mais quentes no município, as temperaturas médias variam entre $24^{\circ} \mathrm{C}$ e $30^{\circ} \mathrm{C}$. Novembro e dezembro, entretanto, são os meses mais secos, e, entre julho e agosto, as temperaturas médias máximas são de $27^{\circ} \mathrm{C}$, e as médias mínimas, de $21^{\circ} \mathrm{C}$.

Em Aracaju, o bairro Porto Dantas apresenta isolamento parcial, sendo limitado geograficamente pelo rio Sergipe, pelo ecossistema costeiro manguezal e pela área de proteção ambiental Morro do Urubu. Trata-se de bairro residencial com poucas casas comerciais situadas ao longo da avenida principal. As casas comerciais, porém, são também utilizadas como residência pelos moradores da localidade. Embora a maioria dos imóveis seja construída de alvenaria, algumas residências em área de invasão são erguidas a partir de materiais como madeira, restos de construção, papelão e lonas plásticas, sem revestimento de piso, sendo de chão batido. No bairro, são encontradas ruas sem pavimentação, e há insuficiência de infraestrutura urbana relacionada às redes de esgoto e de fornecimento de água.

\section{Levantamentos entomológicos}

Para identificação dos imóveis com focos de Ae. aegypti no intra e no peridomicílio, três le- 
vantamentos entomológicos foram realizados na localidade em três períodos distintos: antes, durante e após a epidemia de dengue e em diferentes condições de precipitação. O primeiro levantamento foi realizado em setembro de 2007, período anterior à epidemia e com precipitação mensal de $63,1 \mathrm{~mm}$, marcando o fim da estação chuvosa. No segundo levantamento, realizado entre fevereiro e março de 2008, no início da epidemia e do período chuvoso, foram registrados 226,6mm de precipitação média mensal, e, em novembro de 2008, período posterior à epidemia, $17,7 \mathrm{~mm}$ de precipitação mensal marcaram a fase de estiagem.

As visitas foram realizadas em todos os imóveis do bairro nos dias de segunda a sexta, e, aos finais de semana, foram revisitadas as casas inicialmente fechadas. Todos os recipientes com potencial para se tornar criadouro foram investigados, e as formas imaturas encontradas foram coletadas com o uso de pipetas e de pesca larva e conduzidas ao Laboratório de Parasitologia para quantificação e identificação, sendo as larvas e pupas acondicionadas em copos plásticos separadamente para que os imaturos em estádio $\mathrm{L}_{4}$ que virassem pupas no decorrer do percurso não fossem quantificados como pupas coletadas em campo.

Foram considerados como criadouros positivos os depósitos contendo formas imaturas do vetor e como criadouros potenciais aqueles com armazenamento de água, não hermeticamente fechados, com condições favoráveis ao desenvolvimento de formas imaturas de Ae. aegypti. A quantidade de criadouros por imóvel positivo também foi registrada. Foram considerados como imóveis positivos aqueles que apresentavam alguma forma imatura do vetor, independente da quantidade e do estágio de desenvolvimento dos imaturos. Para determinação dos imóveischave, foram associadas duas variáveis: frequência de positividade e presença de pupas. Assim, foram identificados como imóveis-chave aqueles positivos em mais de um levantamento e que apresentassem pupas em, pelo menos, uma das visitas. É válido considerar a presença de pupas como indicativo da população de mosquitos alados, uma vez que as pupas constituem fase de resistência do mosquito, têm curta duração e são o estágio de desenvolvimento exatamente anterior ao surgimento do adulto.

\section{Análise dos dados}

As informações dos levantamentos entomológicos foram registradas em fichas de campo e transferidas para o banco de dados criado a partir do programa EpiData, versão 3.1 (Epidata As- sociation, Odense, Dinamarca). As informações foram digitadas em duplicata para redução de erros na entrada de dados. Para a análise, utilizou-se o programa Epi Info, versão 3.4.3 (Centers for Disease Control and Prevention, Atlanta, Estados Unidos). Foram realizados o cálculo da razão de chances (OR) e o teste qui-quadrado, com nível de confiança de 0,05, para avaliar se as residências positivas no primeiro levantamento apresentavam maior risco de estarem positivas no segundo.

Para a análise da distribuição espacial, foi realizado o georreferenciamento de todas as casas positivas do bairro em cada um dos levantamentos. O método utilizado para a localização geográfica foi o posicionamento instantâneo de um ponto coletado por meio de um receptor GPS (Global Positioning System) de navegação, marca GARMIN (Garmin, Olathe, Estados Unidos), considerando, no mínimo, quatro satélites rastreados. Os pontos foram importados para o software TerraView 4.1 (Instituto Nacional de Pesquisas Espaciais; http://www.dpi.inpe.br/terra view) para a realização da estatística espacial. A malha digital do bairro Porto Dantas com as divisões dos quarteirões foi adquirida por intermédio da Secretaria de Planejamento de Aracaju (SEPLAN). Foram gerados mapas temáticos, baseados na análise de kernel que constrói gradientes cromáticos em torno dos eventos, indicando, por hot spots ou "áreas quentes", os locais onde há maior risco para a hipótese proposta. A função de suavização utilizada foi a quártica, com largura de banda de 200m. As áreas de influência ("buffer") foram construídas considerandose raio de $200 \mathrm{~m}{ }^{20}$ para análise da dispersão dos mosquitos partindo dos imóveis-chave.

\section{Resultados}

Em todos os levantamentos, mais de $70 \%$ (70,5\% a $77,9 \%$ ) dos imóveis existentes no bairro foram vistoriados. A quantidade de imóveis e de criadouros positivos apresentou redução a cada novo levantamento, embora a oferta de criadouros potenciais permanecesse elevada. A quantidade de imaturos durante os levantamentos também diminuiu, porém larvas e pupas apresentaram reduções diferenciadas. Entre os dois primeiros levantamentos, a redução no número de imóveis positivos não foi acompanhada de redução na quantidade de pupas, embora o número de imóveis positivos e de imaturos tenha diminuído significativamente no terceiro levantamento (Tabela 1).

A distribuição espacial dos imóveis positivos em cada levantamento realizado indica áreas de 
Caracterização dos três levantamentos entomológicos realizados no bairro Porto Dantas. Aracaju, Sergipe, Brasil, 2007/2008.

\begin{tabular}{lccc}
\hline Variáveis & Primeiro & $\begin{array}{c}\text { Levantamentos } \\
\text { Segundo }\end{array}$ & Terceiro \\
\hline Imóveis do bairro & 1.094 & 1.134 & 1.164 \\
Imóveis examinados (\%) & $853(77,9 \%)$ & $863(76,1 \%)$ & $821(70,5 \%)$ \\
Imóveis positivos & 105 & 69 & 12 \\
Criadouros potenciais & 1.334 & 1.235 & 1.078 \\
Criadouros positivos & 130 & 76 & 14 \\
Total de larvas & 12.929 & 7.985 & 870 \\
Total de pupas & 537 & 547 & 7 \\
Precipitação mensal $(\mathrm{mm})$ & 63,1 & 226,8 & 17,7 \\
\hline
\end{tabular}

maior risco concentradas na parte sul e central do bairro na primeira visita. Já na segunda, as áreas de risco encontram-se mais dispersas, atingindo as extremidades da área, enquanto, na terceira visita, há baixa infestação, limitada à região sul do bairro (Figura 1).

Dos 186 imóveis positivos nos levantamentos, 90 (48\%) apresentavam pupas. Apesar de a quantidade de pupas entre os dois primeiros levantamentos não diferir significativamente ( $p>0,05$ ), o número de imóveis com pupas no primeiro foi maior que no segundo. A média de pupas por imóvel passou de cinco no primeiro levantamento para oito no segundo e 0,5 no terceiro. As áreas de risco para imóveis positivos e presença de pupas foram similares nos dois primeiros levantamentos, porém, essas áreas diferiram na última visita (Figuras 1 e 2). A quantidade de criadouros por imóvel positivo não apresentou diferença significativa entre as visitas, sendo encontrada a média de um criadouro por imóvel positivo em todos os levantamentos. Quando foi verificada a distribuição segundo a quantidade de criadouros, observou-se tendência de concentração de imóveis com maior número de criadouros na extremidade sul do bairro (Figura 3). Além disso, a distribuição dos imóveis com pupas não se relacionou com a distribuição dos imóveis contendo três criadouros ou mais (Figuras 2 e 3).

Segundo o critério preestabelecido, foram identificados 13 imóveis-chave no bairro, 1,3\% do total de imóveis analisados, nos quais foram encontradas 323 pupas, o que representa $30 \%$ do total de pupas coletadas nos três levantamentos. A quantidade de pupas por imóvelchave apresentou média de 29,3, variando entre duas e 85 pupas. Ainda considerando os três levantamentos, foram encontrados seis imóveis contendo três ou mais criadouros, o equivalente a $0,7 \%$ do total de imóveis investigados, os quais apresentaram média de 9,6 pupas por imóvel, variando entre zero e 24 pupas. A análise espacial revelou que os imóveis-chave apresentam tendência de agrupamento na área próxima ao centro do bairro, embora estejam presentes em outras partes da localidade, o que possibilita que os mosquitos adultos oriundos desses imóveis se dispersem por todo o bairro, chegando a alcançar áreas vizinhas (Figura 4). A análise da dispersão dos mosquitos a partir desses imóveis, considerando raio de $200 \mathrm{~m} 21$, indicou que, em pouco tempo, eles podem infestar toda a área estudada, já que o bairro apresenta condições favoráveis como áreas de urbanização precária com a existência de invasões de terra e fatores climáticos ideais como temperatura, umidade e índices de precipitação.

A maior parte $(70,5 \%)$ dos criadouros encontrados nos imóveis positivos referia-se a recipientes utilizados pelos moradores da localidade para armazenamento de água. A porcentagem restante estava representada por utensílios reutilizáveis ou descartáveis.

Embora nenhum imóvel permanecesse positivo em todos os levantamentos, a avaliação da positividade entre o primeiro e o segundo levantamento indicou que as casas positivas na primeira visita apresentaram maior risco de estarem positivas também na segunda $[\mathrm{OR}=1,63$ $(1,18<$ OR $<2,26)$ e $\mathrm{p}=0,003]$.

\section{Discussão e conclusão}

Altas infestações por Ae. aegypti despertam preocupação visto que constituem um dos fatores que proporcionam a ocorrência de epidemias de 
Mapa de kernel da distribuição dos imóveis positivos para Aedes aegypti no bairro Porto Dantas por levantamento entomológico. Aracaju, Sergipe, Brasil, $2007 / 2008$.

1a) 1 의 levantamento

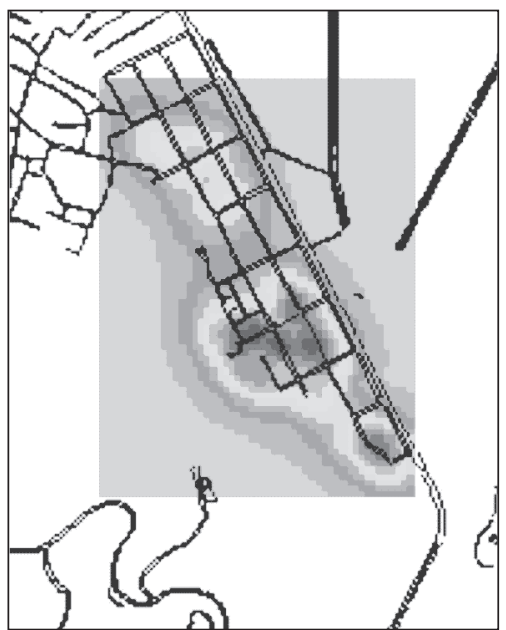

Valores de kernel

Menor

Maior
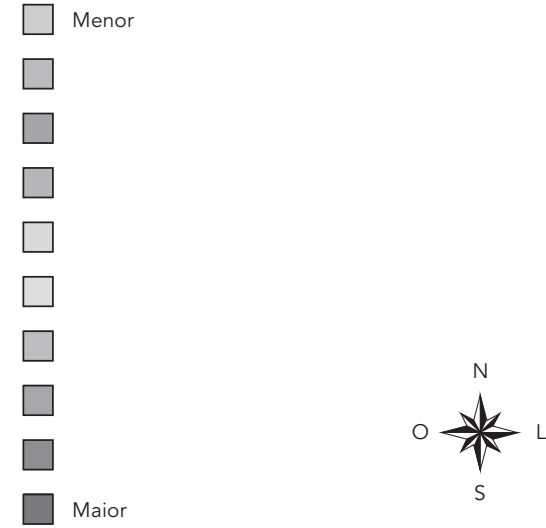

1b) 2o levantamento

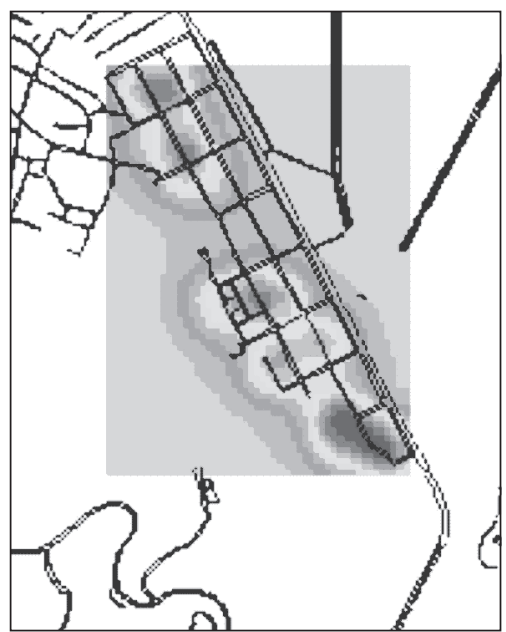

1c) 3o levantamento

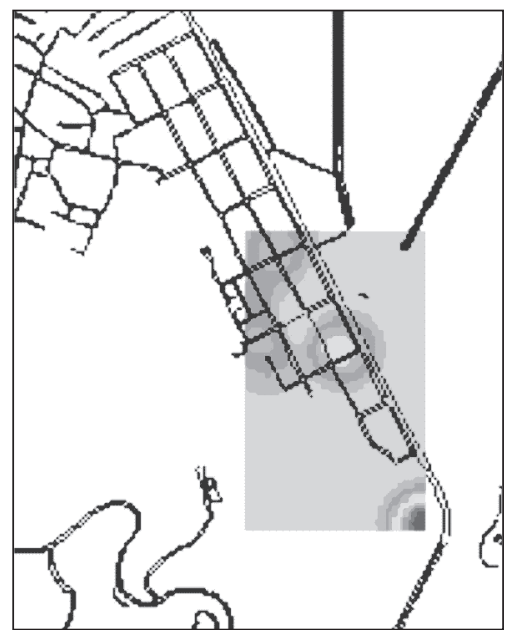

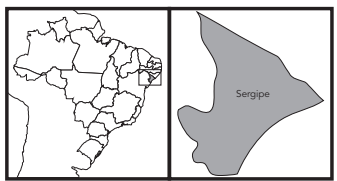

0

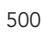

1.000

dengue. A presença do vetor, associada a condições ambientais favoráveis, determina a sazonalidade da doença em muitas localidades 22 . Nos dois primeiros levantamentos realizados neste estudo, houve alta infestação por formas imaturas de Ae. aegypti em comparação com o terceiro, quando a quantidade de imaturos diminuiu consideravelmente. O primeiro levantamento, realizado em período anterior à epidemia e final do período chuvoso, apresentou maior número de imóveis positivos em relação ao segundo, realizado em período marcado pelo início das chuvas e epidemia de dengue. Porém, durante o segundo levantamento, período epidêmico, a proporção de pupas por imóvel positivo quase dobrou em relação ao anterior, o que sugere que a produtividade dos imóveis é melhor representativa do risco de ocorrência da doença que a simples positividade, visto que essa considera somente a presença de imaturos do vetor, independente do estágio de desenvolvimento, o que não reflete a real produção de mosquitos adultos. Vários autores têm considerado a presença de pupas como indicativo da população de mosquitos adultos 12,23,24.

Estudos têm mostrado relação entre precipitação pluviométrica mensal, incidência de focos de Ae. aegypti e casos de dengue 10,20,22, ressaltan- 
Mapa de kernel da distribuição dos imóveis com pupas de Aedes aegypti no bairro Porto Dantas por levantamento entomológico. Aracaju, Sergipe, Brasil, 2007/2008.

2a) 1ㅇ levantamento

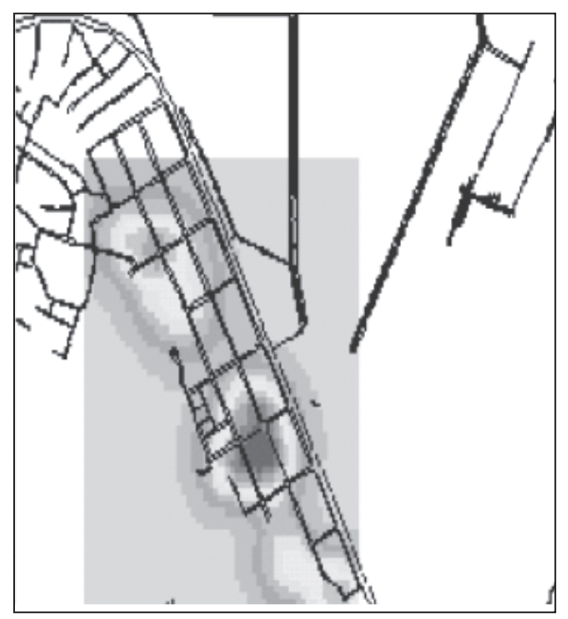

2b) 2o levantamento

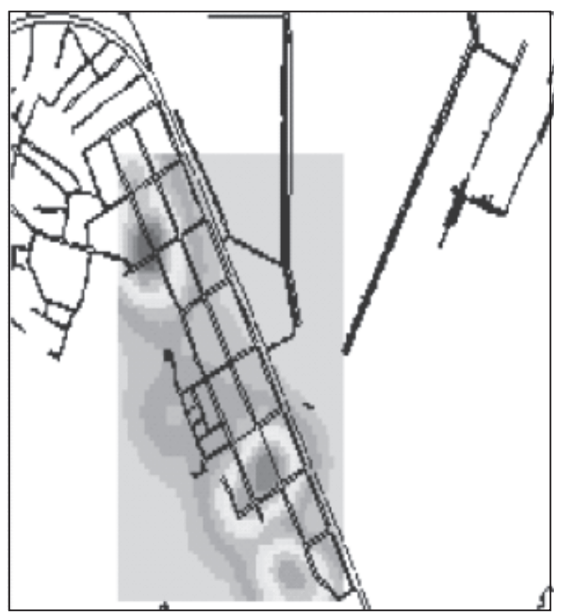

2c) 3이 levantamento

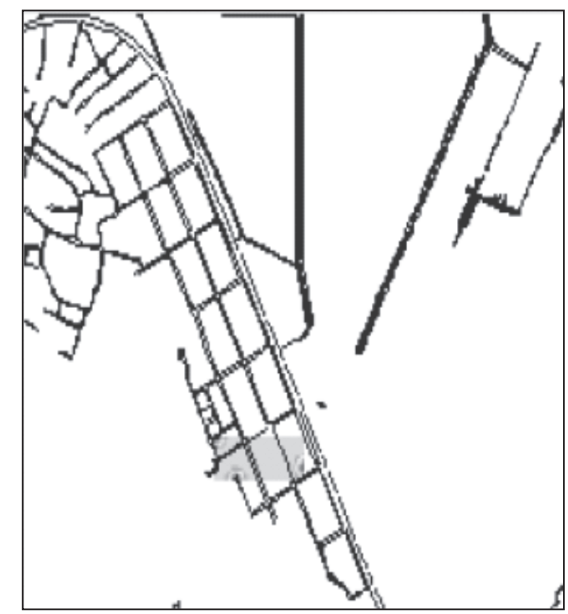

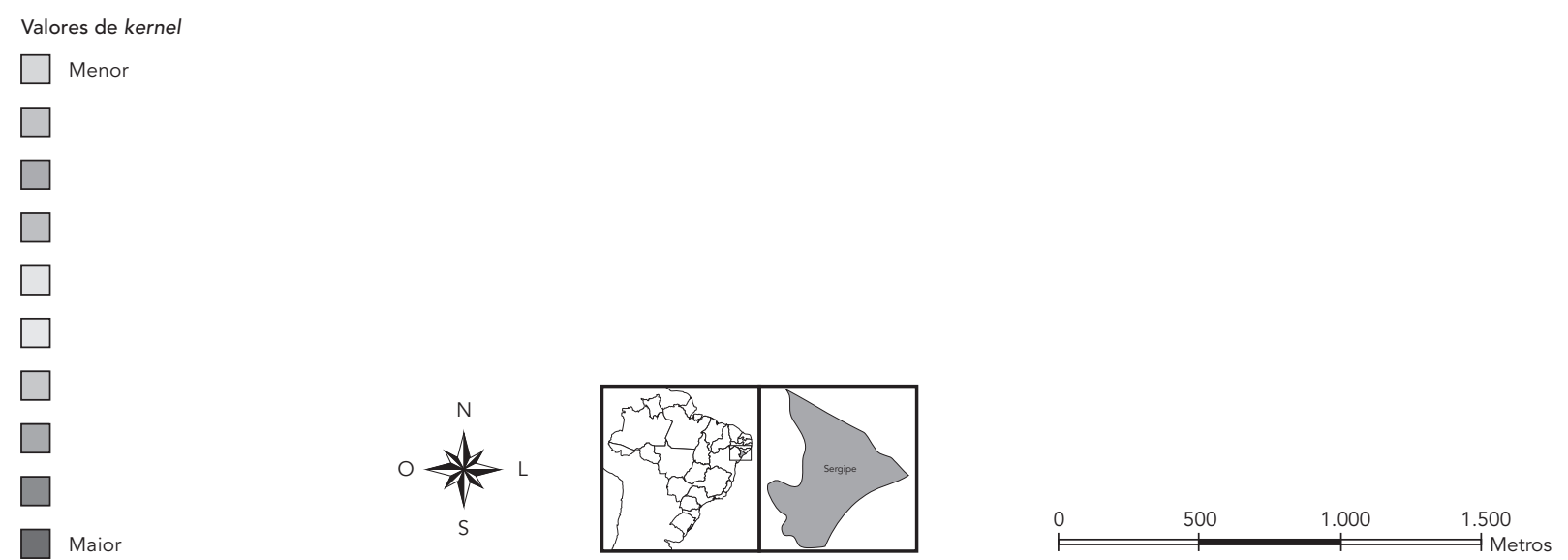

do a estreita ligação entre a doença transmitida por vetores e as variações climáticas, embora, em alguns casos, os fatores abióticos de determinado mês estejam correlacionados com o número de casos da doença no mês seguinte 25 , situação observada em Aracaju no mês seguinte à realização do segundo levantamento entomológico. Nesse levantamento, executado entre os meses de fevereiro e março de 2008, período de início das chuvas, observou-se maior densidade de pupas, e, em abril do mesmo ano, a epidemia de dengue atingiu o auge. Com temperatura média anual de $26^{\circ} \mathrm{C}$, o Município de Aracaju oferece as condições ambientais propícias à infestação do vetor da dengue. Além disso, o início do período chuvoso é ainda mais favorável à proliferação do vetor, uma vez que há precipitação para manter os criadores mas não o suficiente para possibilitar que os mesmos transbordem por excesso de água.

Na primeira visita, os imóveis positivos estavam mais concentrados próximo à área central do bairro, o mesmo ocorrendo com as pupas, enquanto, na segunda visita, houve vários pontos de risco em diferentes localidades, tanto para as pupas como para os imóveis. Considerando que nesse segundo levantamento também ocorreu maior densidade de pupas por imóvel positivo, 
Mapa da distribuição dos imóveis por número de criadouros positivos de Aedes aegypti no bairro Porto Dantas por levantamento entomológico. Aracaju, Sergipe, Brasil, 2007/2008.
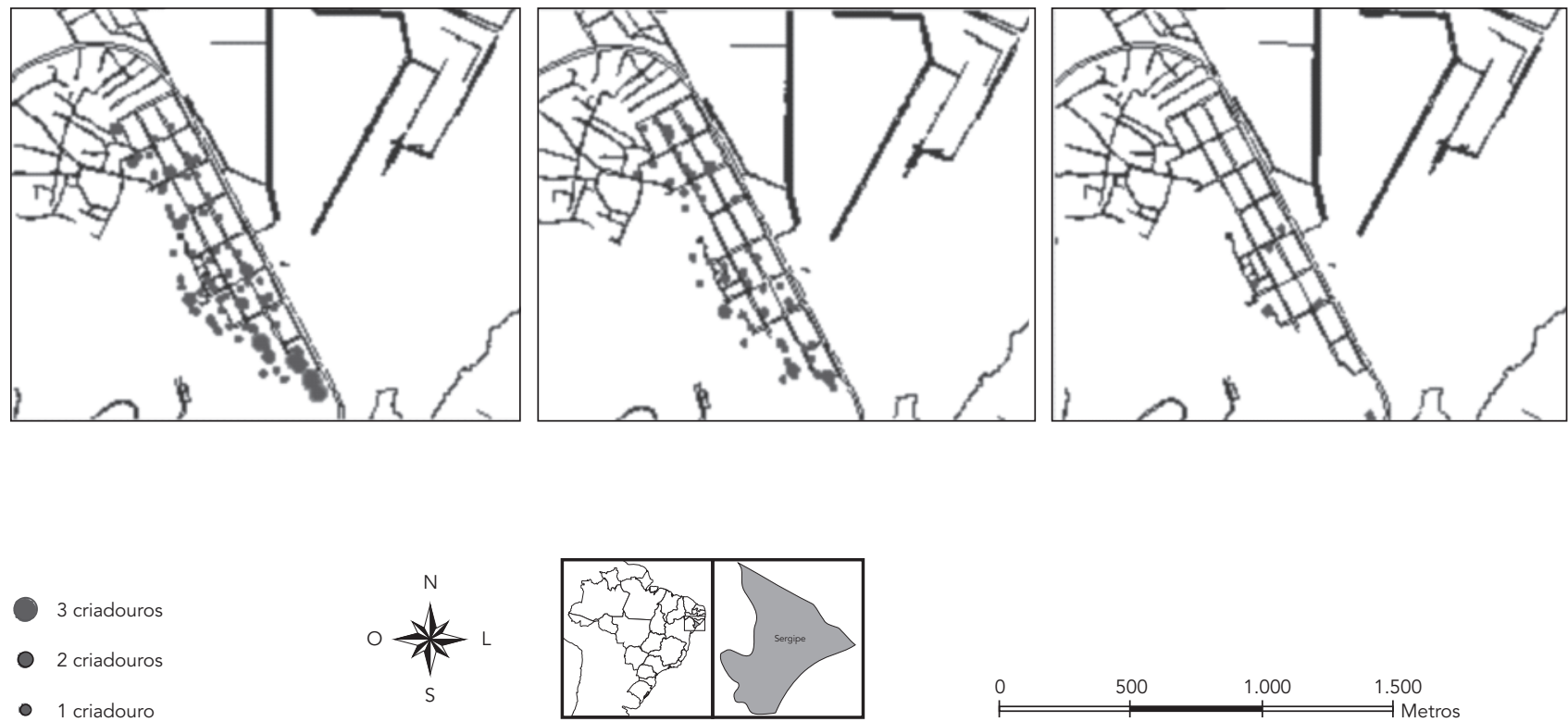

deduz-se que os mosquitos adultos estavam mais dispersos. No terceiro levantamento, realizado em período de seca e posterior à epidemia, houve visível redução na infestação. Porém, apesar de a quantidade de focos do mosquito reduzir drasticamente, a existência de imóveis com criadouros localizados na região sul do bairro pode manter a presença do vetor mesmo em condições ambientais desfavoráveis. A distribuição das pupas nesse último levantamento também indicou concentração nos imóveis da parte sul do bairro. A manutenção da infestação por Ae. aegypti no bairro nesse período de seca pode estar associada à presença de recipientes destinados ao armazenamento de água, visto que esses foram predominantes na localidade e acumulam água independente dos níveis de precipitação. Além disso, a concentração de imóveis positivos na porção sul do bairro na terceira visita poderia ser explicada pela dinâmica crescente da área com surgimento de casas em terrenos invadidos, oferecendo condições propícias à proliferação do vetor, sendo que nem todas as residências aí fixadas são beneficiadas pela rede de abastecimento de água.
Assim, durante o período do estio, a infestação parece limitar-se a pequeno número de imóveis, concentrados em área específica do bairro, para então se expandir quando o ambiente for favorável. Esse seria, então, o momento ideal para adoção de práticas que interrompessem a conclusão do ciclo de vida do mosquito e impedissem a manutenção da infestação, visto que não seria necessário trabalhar em toda a localidade, mas apenas nos pontos de concentração específicos, o que poderia otimizar tempo, mão de obra e recursos.

Não houve associação entre as áreas contendo imóveis com presença de pupas e aquelas contendo imóveis com três ou mais criadouros. Em Porto Dantas, das 1.091 pupas coletadas nos três levantamentos, 5,3\% estavam presentes nos imóveis com maior número de criadouros, o que sugere que a presença de muitos criadouros no imóvel não significa maior produção de adultos, reforçando a necessidade de considerar a presença de pupas para melhor estimar a população de adultos.

Os 13 imóveis-chave identificados no bairro podem ser considerados como os mais implica- 
Figura 4

Mapa da distribuição dos imóveis-chave para Aedes aegypti no bairro Porto Dantas (4a) e buffer da dispersão dos mosquitos adultos a partir desses imóveis (4b). Aracaju, Sergipe, Brasil, 2007/2008.

4a) Imóveis-chave

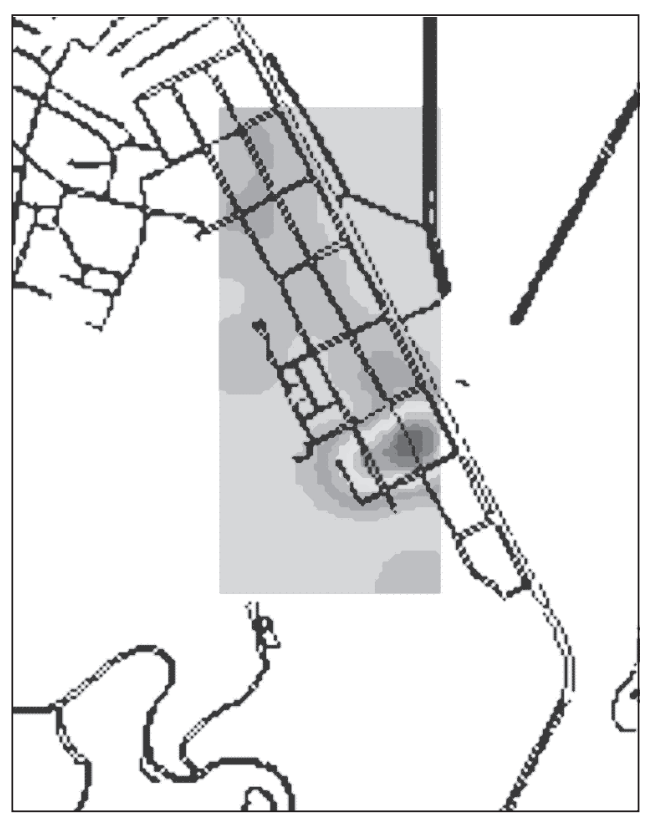

Valores de kernel

$\square$ Menor

$\square$

$\square$

$\square$

$\square$

$\square$

$\square$

$\square$

$\square$

$\square$ Maior 4b) Dispersão dos mosquitos adultos

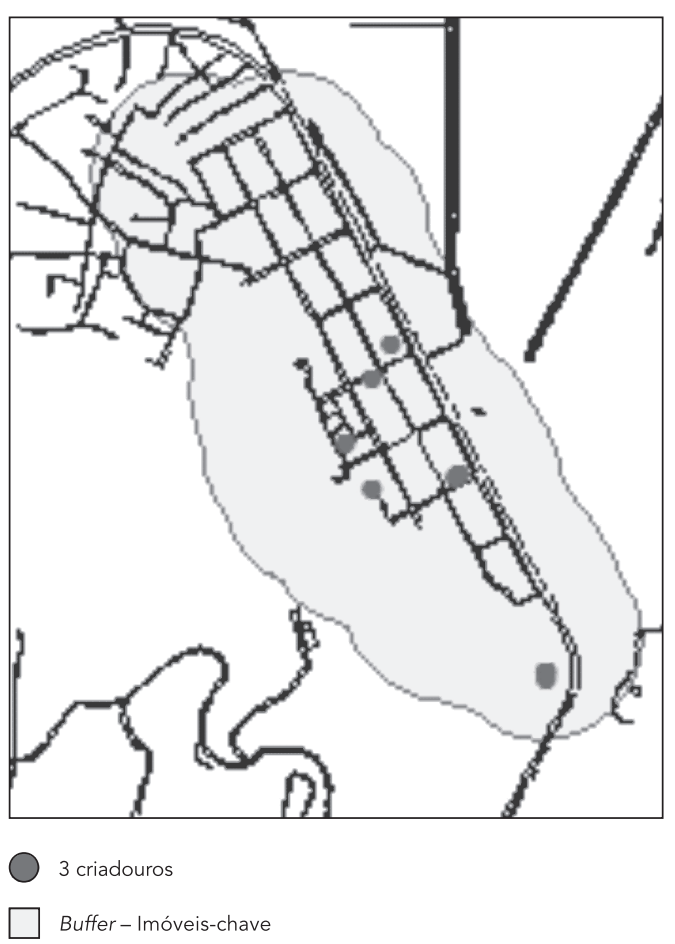

$0 \frac{1}{s}$

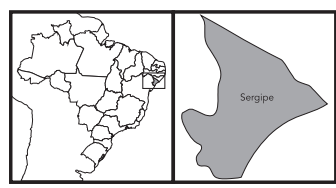

500

$1.000 \quad 1.500$

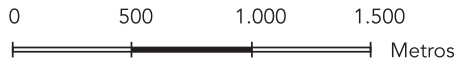


dos na infestação da localidade, uma vez que, apesar de representarem apenas 1,3\% do total de imóveis analisados, foram responsáveis por um terço do total de pupas encontradas, mantendo a infestação independente das condições ambientais. Pesquisa realizada na mesma localidade em período próximo ao presente trabalho, porém considerando a infestação de mosquitos adultos pela utilização de armadilhas tipo MosquiTRAP 26, constatou maior densidade de alados na área onde estão concentrados os imóveis-chave identificados neste estudo, reforçando a importância epidemiológica desses imóveis.

Assim, os imóveis-chave possibilitam condições para que o vetor complete o seu ciclo de vida, aumentando, dessa forma, as chances de transmissão da dengue e merecem, portanto, prioridade nas ações de controle do vetor e vigilância constante, especialmente no período marcado pelo início das chuvas, quando tendem a ser mais produtivos. Diversos autores reforçam que a efetividade do controle terá mais resultado se forem priorizadas áreas com maior produção de mosquitos 27,28,29,30,31.

Na Austrália, Tun-Lin et al. 32 estudaram os diferentes tipos de recipientes contendo formas imaturas de Ae. aegypti e classificaram como focos geradores os estabelecimentos contendo três ou mais criadouros do mosquito. Naquela localidade, 46 focos geradores, que correspondiam a $3 \%$ do total de imóveis analisados, foram responsáveis por metade dos recipientes positivos. Esse conceito de foco gerador, porém, se aplicado em Aracaju, não expressaria as áreas de maior importância epidemiológica. Portanto, como cada região apresenta particularidades que interferem na dinâmica da infestação, os indicadores de risco não devem envolver critérios universais aplicáveis em diferentes regiões, mas prescindir sempre de informações locais que expressem a real situação epidemiológica.

O risco de um imóvel apresentar criadouros em levantamentos sucessivos reforça a necessidade de priorizar esses imóveis nas atividades de vigilância entomológica e nas campanhas de informação e mobilização social para orientar os moradores, visto que os moradores tendem a manter seus hábitos de armazenamento de água, e que os criadouros podem se apresentar sistematicamente nas mesmas residências.

A análise espacial tanto dos imóveis positivos quanto da distribuição de pupas possibilitou verificar a dinâmica da infestação na localidade ao longo dos três levantamentos. No entanto, os resultados aqui apresentados devem ser considerados com cautela, já que a perda de cerca de $30 \%$ dos domicílios pode ter gerado distorções nos resultados das análises realizadas se existir alguma seletividade nessas pendências em termos dos indicadores entomológicos analisados e em termos da sua distribuição geográfica.

A metodologia utilizada nesta pesquisa é aplicável à rotina do serviço de saúde em qualquer localidade, visto que é prática, não exige muita mão de obra e possibilita concluir o trabalho na área estudada em curto espaço de tempo. Além disso, o uso da técnica de geoprocessamento para identificação da distribuição de imóveis positivos e produtivos constitui critério válido para caracterizar a infestação por Ae. aegypti e direcionar as ações de controle vetorial.

\section{Resumen}

La mejor forma de evitar nuevas epidemias de dengue es controlar el vector, el mosquito Aedes aegypti. Por ello, este estudio tuvo por objetivo identificar y analizar la distribución espacial de los recipientes-clave para Ae. aegypti en Aracaju, Sergipe, Brasil. Con este fin, tres estudios entomológicos se realizaron en períodos anteriores, durante y después de la epidemia de dengue y en diferentes condiciones de precipitación pluvial: fin del período lluvioso, inicio de la estación de lluvias y período seco. Para identificar los recipientesclave, se consideraron las variables: positividad en más de un estudio y presencia de crisálidas; y para verificar la distribución espacial y la dispersión de los mosqui- tos, se realizó un análisis de padrones puntuales, por medio del estimador de densidad de kernel y buffer. Se constató que los recipientes-clave son responsables del mantenimiento de la infestación en la localidad, independientemente de las condiciones ambientales y del período epidémico, además, son focos generadores de mosquitos que pueden dispersarse hacia áreas vecinas del barrio. De esta forma, las acciones de control vectorial, para ser más efectivas, deben estar dirigidas hacia esos inmuebles.

Dengue; Aedes; Sistemas de Información Geográfica; Control de Vectores 


\section{Colaboradores}

L. S. Marteis colaborou na aquisição, análise e interpretação dos dados, além da revisão crítica do conteúdo intelectual e redação do artigo. L. M. Steffler colaborou na análise e interpretação dos dados, bem como na redação do artigo. K. C. G. M. Araújo contribuiu para o design, a aquisição, análise e interpretação dos dados e redação do artigo. R. L. C. Santos colaborou para análise e interpretação dos dados, revisão crítica do conteúdo intelectual e redação do artigo.

\section{Referências}

1. Teixeira MG, Barreto ML, Guerra Z. Epidemiologia e medidas de prevenção do dengue. Inf Epidemiol SUS 1999; 8:5-33.

2. Silva Júnior JB, Siqueira Júnior JB, Coelho GE, Vilarinhos PT, Pimenta-Júnior FG. Dengue in Brazil: current situation and control activities. Epidemiol Bull 2002; 23:3-6.

3. Pessanha JEM, Caiaffa WT, César CC, Proietti FA. Avaliação do Plano Nacional de Controle da Dengue. Cad Saúde Pública 2009; 25:1637-41.

4. Souza-Santos R, Carvalho MS. Spatial analysis of Aedes aegypti larval distribution in the Ilha do Governador neighborhood of Rio de Janeiro, Brazil. Cad Saúde Pública 2000; 16:31-42.

5. Lourenço-de-Oliveira R, Vazeille M, Filippis AM, Failloux AB. Aedes aegypti in Brazil: genetically differentiated populations with high susceptibility to dengue and yellow fever viruses. Trans R Soc Trop Med Hyg 2004; 98:43-54.

6. Secretaria de Vigilância em Saúde, Ministério da Saúde. Programa Nacional de Controle da Dengue. Informe epidemiológico da dengue. Semanas de 1 a 30 de 2009. Brasília: Ministério da Saúde; 2009.

7. Braga IA, Valle D. Aedes aegypti: vigilância, monitoramento da resistência e alternativas de controle no Brasil. Epidemiol Serv Saúde 2007; 16:295-302.

\section{Agradecimentos}

Agradecemos o apoio financeiro do CNPq e Ministério da Saúde (CNPq/DECIT 410542/2006-7) e à CAPES pela concessão de bolsa às alunas L. S. Marteis e L. M. Steffler
8. Braga IA, Gomes AC, Nelson M, Mello RCG, Bergamaschi DP, Souza JMP. Comparação entre pesquisa larvária e armadilha de oviposição, para detecção de Aedes aegypti. Rev Soc Bras Med Trop 2000; 33:347-53.

9. Donalísio MR, Glasser CM. Vigilância entomológica e controle de vetores do dengue. Rev Bras Epidemiol 2002; 5:259-72.

10. Gomes AC. Entomologic surveillance. Inf Epidemiol SUS 2002; 11:79-90.

11. Lagrotta MTF, Silva WC, Souza-Santos R. Identificação de áreas chave para o controle de Aedes aegypti por meio de geoprocessamento em Nova Iguaçu, Estado do Rio de Janeiro, Brasil. Cad Saúde Pública 2008; 24:70-80.

12. Brito M, Forattini OP. Produtividade de criadouros de Aedes albopictus no Vale do Paraíba, SP, Brasil. Rev Saúde Pública 2004; 38:209-15.

13. Mondini A, Chiaravalloti Neto F, Sanches MGY, Lopes JCC. Spatial analysis of dengue transmission in a medium sized city in Brazil. Rev Saúde Pública $2005 ; 39: 444-51$. 
14. Souza LJ, Ribeiro EF, Barros AR, Siqueira R. Centro de controle de zoonoses e vigilância ambiental e estratégias técnica e operacional para o controle do Aedes aegypti no Município de Campos dos Goytacazes - RJ. In: Souza LJ, editor. Dengue: diagnóstico, tratamento e prevenção. 2a Ed. Rio de Janeiro: Editora Rubio; 2008. p. 125-68.

15. Medronho RA. Geoprocessamento e saúde: uma nova abordagem do espaço no processo saúdedoença. Rio de Janeiro: Núcleo de Estudos em Ciência e Tecnologia, Fundação Oswaldo Cruz; 1995.

16. Organização Pan-Americana da Saúde. Sistema de informação geográfica em saúde: conceitos básicos. Brasília: Organização Pan-Americana da Saúde; 2002.

17. Barcellos C, Pustai AK, Weber MA, Brito MRV. Identificação de locais com potencial de transmissão de dengue em Porto Alegre através de técnicas de geoprocessamento. Rev Soc Bras Med Trop 2005; 35:246-50.

18. Machado JP, Oliveira RM, Souza-Santos R. Análise espacial da ocorrência de dengue e condições de vida na cidade de Nova Iguaçu, Estado do Rio de Janeiro, Brasil. Cad Saúde Pública 2009; 25: 1025-34.

19. Secretaria de Vigilância em Saúde, Ministério da Saúde. Sistema Nacional de Vigilância em Saúde. Relatório de situação: Sergipe. Brasília: Ministério da Saúde; 2009.

20. Oliveira MMF. A dengue em Curitiba/PR: uma abordagem climatológica do episódio de março/ abril - 2002. Revista R. RA`E GA: O Espaço Geográfico em Análise 2002; (8):45-54.

21. Maciel-De-Freitas R, Codeço CT, Lourenço-DeOliveira R. Daily Survival rates and dispersal of $A e$ des aegypti females in Rio de Janeiro, Brasil. Am J Trop Med Hyg 2007; 74:659-65.

22. Lima EA, Firmino JLN, Gomes Filho MF. A relação da previsão da precipitação pluviométrica e casos de dengue nos estados de Alagoas e Paraíba, Nordeste do Brasil. Revista Brasileira de Meteorologia 2008; 23:264-8.

23. Focks DA, Sackett SR, Bailey DL, Dame DA. Observations on container-breeding mosquitoes in New Orleans, Louisiana, with an estimate of the population density of Aedes aegypti (L.). Am J Trop Med Hyg 1981; 30:1329-35.
24. Focks DA, Chadee DD. Pupal survey: an epidemiologically significant surveillance method for Aedes aegypti: an example using data from Trinidad. Am J Trop Med Hyg 1997; 56:159-67.

25. Ribeiro AF, Marques GRA, Voltolini JC, Condino MLA. Associação entre incidência de dengue e variáveis climáticas. Rev Saúde Pública 2006; 40:671-6.

26. Steffler LM, Marteis LS, Dolabella SS, Cavalcanti $\mathrm{SCH}$, Santos RLC. Risk of dengue occurrence based on the capture of gravid Aedes aegypti females using MosquiTRAP. Mem Inst Oswaldo Cruz 2011; 106:365-67.

27. Foratini OP, Kakitani I, Sallum MAMM, Rezende L. Productivity of container-breeding Aedes albopictus in an urban environment. Rev Saúde Pública 1997; 31:545-55.

28. Medronho RA. Dengue e o ambiente urbano. Rev Bras Epidemiol 2006; 9:159-61.

29. Medronho RA, Macrini L, Novellino DM, Lagrotta MTF, Câmara VM, Pedreira CE. Aedes aegypti immature forms distribution according to type of breeding site. Am J Trop Med Hyg 2009; 80:401-4.

30. Tun-Lin W, Lenhart A, Nam VS, Rebollar-Téllez E, Morrison AC, Barbazan P, et al. Reducing costs and operational constraints of dengue vector control by targeting productive breeding places: a multicountry non-inferiority cluster randomized trial. Trop Med Inter Health 2009; 14:1143-53.

31. Maciel-de-Freitas R, Lourenço-de-Oliveira R. Does targeting key-containers effectively reduce Aedes aegypti population density? Trop Med Int Health 2011; 16:965-73.

32. Tun-Lin W, Kay BH, Barnes A. Understanding productivity, a key to Aedes aegypti surveillance. Am J Trop Med Hyg 1995; 53:595-601.

Recebido em 14/Out/2011

Versão final reapresentada em 11/Set/2012 Aprovado em 24/Out/2012 